\title{
Determination of Pesticide Residues Level in Phaseoulus vulgaris Sp. Plant Soil at Cameron Highland
}

\author{
Y.C. WONG ${ }^{1 *}$, N.A.M. ARIFIN ${ }^{1}$ and N.A. ATIQAH ${ }^{1}$ \\ ${ }^{1}$ Faculty of Agro Based Industry, Universiti Malaysia Kelantan, \\ Jeli Campus, Locked Bag 100, 17600 Jeli, Kelantan, Malaysia. \\ ${ }^{*}$ Corresponding author E-mail: yeeching@umk.edu.my \\ http://dx.doi.org/10.13005/ojc/290441
}

(Received: September 27, 2013; Accepted: November 07, 2013)

\begin{abstract}
The application of pesticide is the best method to increase crops production yield. However it is also harmful to human health and the environment. The pesticides tested inthis study were Daconin, AntracolWP70 and Dithane M-45. They contain chlorothalonil, propined and mancozeb. A total of five soil samples were collected at $15 \mathrm{~cm}$ soil depth by systematic sampling.
\end{abstract}

Key words: Pesticide residue, Phaseoulus vulgaris, Plant soil.

\section{INTRODUCTION}

Pesticides are growth regulators that stimulate or retard the growth of plants. Theyfunction as desiccants that speed up the drying of plants, used as an aid in mechanical harvesting of cotton, soybeans and other crops, act as defoliants that remove leaves and aid in the harvesting of potatoes and certain other crops. Pesticides are also used in repelling, attracting, and sterilizing insects'.

Agricultural industry is an important cash crop in Cameron Highland, Pahang. In the tea plantation industry, the pest management involves usage of pesticides to achieve optimum control of weeds. However, the increasing application and amount of pesticides used in agricultural and non-agricultural sectors also caused air and water pollutions.
The direct exposure or indirect exposure to pesticides caused residues in food and drinking water which could lead to more serious environmental problem as well as harmful effects tohuman health. Alarming levels of pesticides inair, water, soil, food and biological materials have been reported. Pesticides can be transferred through run-off, leaching, adsorption, crop removal, degradation and volatilization.

Chlorothalonil is a fungicide typically used on peanuts, tomatoes, potatoes, lawns, turf and roses. The application of chlorothalonilis about 11 million pounds annually, second highest widely used in agricultural and household. Chlorothalonil or 2,4,5,6-tetrachloroisophthalonitrile is a critical tool in fungicide resistant management due to its mode of action $^{2}$. 
Mancozeb is a member of ethylenebisdiothiocarbamate (EBDC) fungicide. It is used to protect many types of fruits, vegetables, nuts and field crops against a wide spectrum of fungal diseases including potato blight, leaf spot, scab and rust. It is available as dust, liquid, water dispersable granules, wettable powders and as ready-to-use formulations ${ }^{3}$.

Chlorothalonilhalf life in soil is 1 to 2 months while the mancozeb is 1 to 7 days ${ }^{4-5}$. The persistence of chlorothalonil is from 200 days to one year ${ }^{6}$ while the persistence of mancozeb is from at least 2 days ${ }^{7}$.

The objectives of the study were to identify chlorothalonil, propined and mancozeb in Daconin, Antracol WP70 and Dithane M-45pesticides used in agricultural sites, to measure the amount of pesticides that penetrated the soils, and to study therelations of the distancesof plantation sites from the soil sample plots. The study also aimed to provide more understanding in the risks and applications of pesticideson agricultural lands.

\section{Methodology}

The soil sampleswere collected from the agricultural plant site of Phaseolus Vulgaris sp.inMARDI Cameron Highland, Pahang. The samples were taken from different plots at variety of depths which were 0 to $5 \mathrm{~cm}, 5$ to $10 \mathrm{~cm}$ and 10 to $15 \mathrm{~cm}$ and were analyzed using High Performance Liquid Chromatography (HPLC).

\section{Soil sample collection}

All the samples were collected using auger and labelled such as S1D1 as plot 1 depth 1 ( 0 to 5 $\mathrm{cm}$ ). Figure 1 showed the locations of the plots.

\section{Soil extraction}

$10 \mathrm{~g}$ of soil samples were weighed and added with $60 \mathrm{~mL}$ of distilled water before agitated in the mechanical shaker for 2 hours followed by filtration process. $10 \mathrm{ml}$ of filtrate solutions were pipetted and centrifuged for 10 minutes at $500 \mathrm{rpm}$ at room temperature. The samples werethen filtered again. Finally, the extracts were analyzed using HPLC.
Table 1: HPLC tests preparations

\begin{tabular}{|c|c|}
\hline Mobile phase & $\begin{array}{l}\text {-Water : Acetonitrile } \\
\text {-ratio (\%): 40:60 }\end{array}$ \\
\hline Flow rate & $1.0 \mathrm{ml} / \mathrm{min}$ \\
\hline Column & $\begin{array}{l}\text { C18(150 mmx4.6 mm } \\
\times 5 \mu \mathrm{m})\end{array}$ \\
\hline Detection wavelength & $\begin{array}{l}\text { Excitation wavelength } \\
365 \mathrm{~nm}\end{array}$ \\
\hline Emission wavelength & $475 \mathrm{~nm}$ \\
\hline Loop/injection volume & $10 \mu \mathrm{l}$ \\
\hline Column temperature & $40 \stackrel{\circ}{C}$ \\
\hline
\end{tabular}

Preparation of standard solution

The pesticides used on the agricultural sites were obtained.

\section{Preparation of HPLC}

The preparations forthe HPLC tests were done as showed in Table 1.

\section{RESULTS AND DISCUSSION}

Figure 2 showed that the highest concentration of chlorothalonilfound was 1999\% (S3D2) and the lowest concentration of chlorothalonil was $1138 \%$ (S1D2). The concentration of the standard solution ofchlorothalonil was $2791622 \%$. The sprayed off pesticides leached downward to the lower soil.The higher density and concentration of pesticides from upper soil layer may leach to the lower soil layer. It may depend on the solubility of the compound, soil structure, water movement and soil interruption via macrosporous and microporous paths. The pesticides deposited in the deepest soil layer showed the highest concentrations.

Figure 2 also showed that as the depths of the soil in plot P5 increased,the concentration of chlorothalonil in soil also increased. The deeper the soils, the more quantity of chlorothalonil found. The drifting of chlorothaloniloutside the intended area when it was sprayed, also knownas spray drift, might have causedchlorothalonil deposition and penetration in the soil. It might also percolate or leached through the soil.If the run-off soil and leaching process happened, the chlorothalonil will be deposited in the drainage and may cause water pollution? 


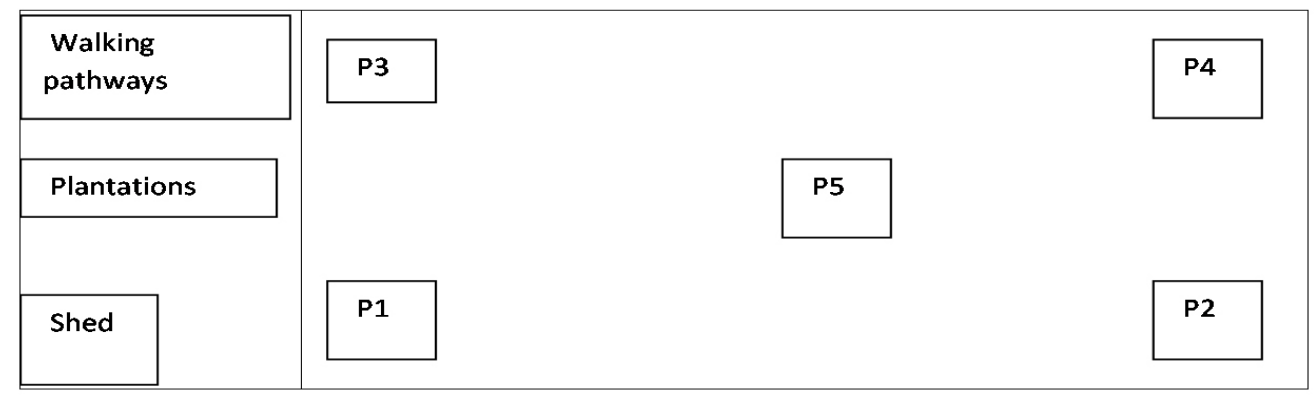

Fig. 1: The location of the sampling plots

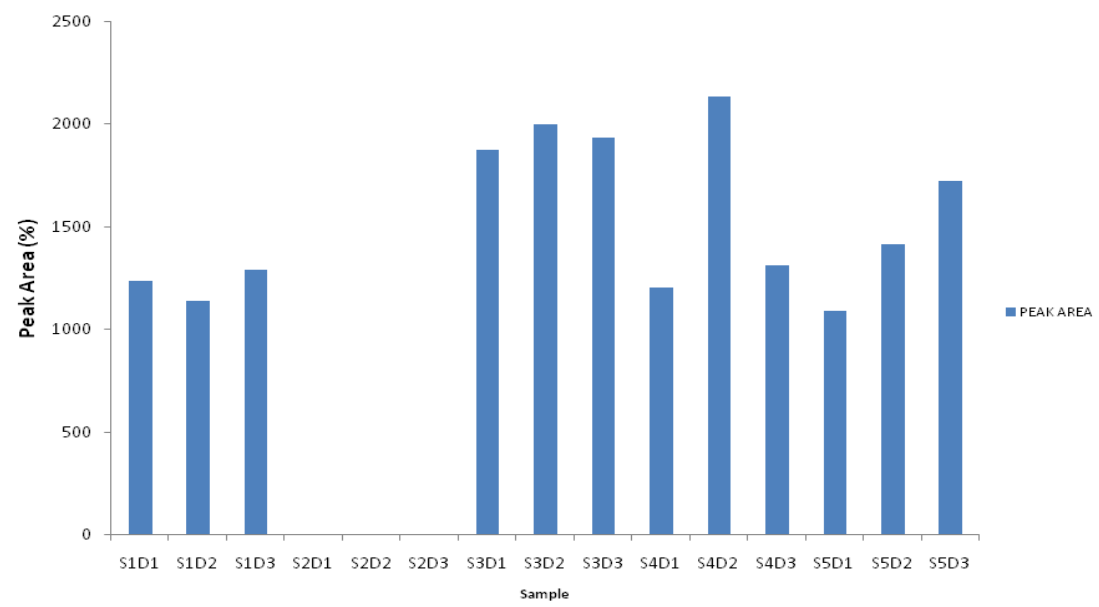

Fig. 2: HPLC results for contamination of chlorothalonil

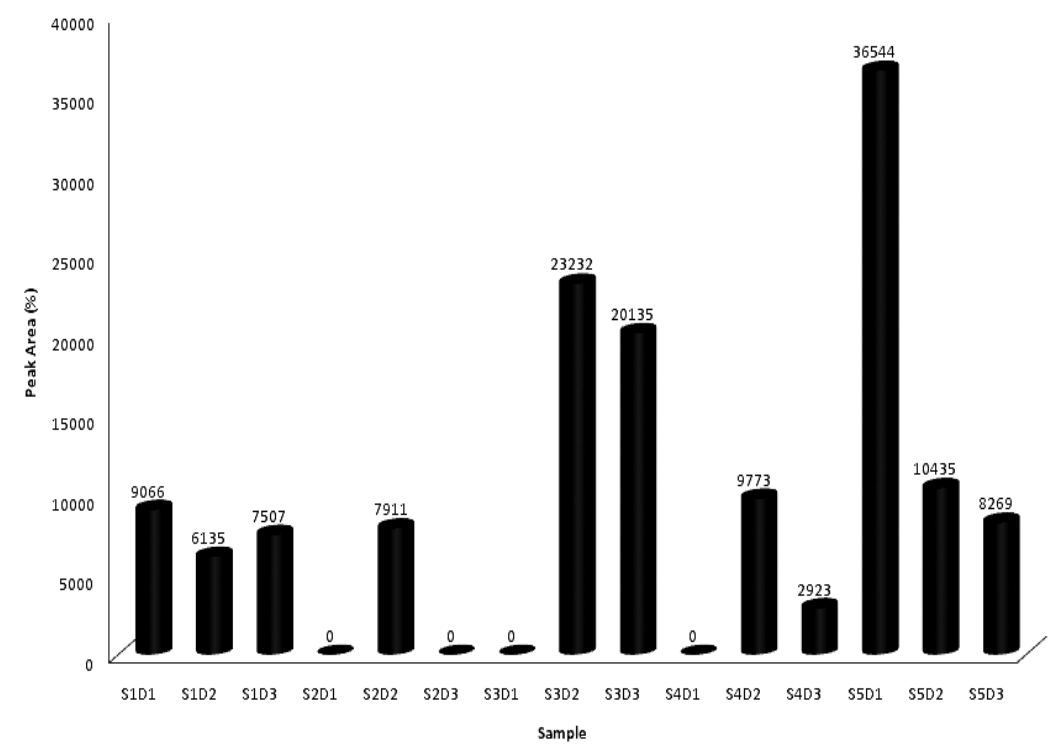

Fig. 3: HPLC results for contamination of mancozeb 
The distances of plot P4 and P2 from the plantation were very far. Plot P2 showed zero readings which also meant that the plot did not contain chlorothalonil. The land run-off, leaching and erosion of soil happened on plot P2 also caused the increased amount of chlorothalonil on plot P4 as the depths of the soil increased.

Fig. 3 showed that the highest concentration of mancozeb was $36544 \%$ (S5D1) while the lowest concentration was $2923 \%$ (S4D3). The concentration of mancozebstandard solution was $443400 \%$. Plot 5 was located at the center and the highest concentration of mancozeb was found at the top soil layer.

The moderate degradation and mobile potential of mancozeb caused it to bind to the soil through adsorption process ${ }^{8}$. Plot P5 contained mancozeb at each soil depths due to mancozeb being insoluble in water but moderately mobile in soil. Spray drift might have occurred because mancozeb exists as dust, granular and liquid forms ${ }^{9}$. The pesticides from plot P3 and P1 flowed from surface run-off due to heavy rain to P5 because the location of P5 was at the center. Mancozeb also has low potential to volatilize into the air because of its negligible vapor pressure ${ }^{10}$. This explained that plot $\mathrm{P} 1$ and P5 contained contaminatedmancozeb.
All of the soil sample plots atdepths 5 to $10 \mathrm{~cm}$ showed contamination of mancozeb. This was due to the degradation of mancozeb which moderately bound to the soil via adsorption process ${ }^{11-}$ 12.

All of the soil sample plots except Plot 2 at depths 10 to $15 \mathrm{~cm}$ showed contamination of mancozeb due to microbial degradation which caused shorterhalf-life of mancozeb. In addition, under aerobic conditions, the hyrolysis degradation were ethylenethiourea (ETU) and ethyleneurea (EU) breakdown further to produce carbon dioxide, $\mathrm{CO}_{2}{ }^{13-14}$. The rate of microbial degradation also increased.

\section{CONCLUSION}

The significance of the concentrations from the three different pesticides based on the amount of pesticides found in the soil samples was very low. The concentrations of these pesticides did not exceed standard acute toxicity for animal, human and plant. However, the increased application of pesticides also increased the crop production yield. Over700 pesticides will be registered for use in the agricultural industry worldwide.

\section{REFERENCES}

1. Bohmort, B.L., Prentice's Hall (2003).

2. Fishel, F., Agriculture MU Guide (1997).

3. Edwars, I.R., Ferry, D.G., and Temple., Academic Press, New York, p. 4-2 (1991).

4. U.S. EPA., Pesticide fact sheet: Chlorothalonil. No. 36. Washington, D.C., Sept. 30 (1986).

5. G. S. Kalwania and R. Shyam., Orient. J. Chem., 28(1): 547-552 (2012).

6. Takagi K., and Wada. H., 14th Intern. Cong. Soil Sci., 3: 196-201 (1990).

7. Getenga, Z.M., Jondiko, J.I.O., Wandiga, S.O. and Beck, E., Environ. Cont. Toxicol., 64: . 356-367 (2000).

8. A.Nag., New Delhi: Prentice. Hall of India
(2006).

9. H.Ghadiri and C.W., Rose. J. Environ. Manage., 62: 155 (2001).

10. Kovach. J., New York's Food and Life Sci. Bull, 139: 1-8 (1992).

11. P.K. Gupta., Toxicology, 198: p.83-90 (2004).

12. Arokiyaraj, R. Vijayakumar and P. M. Devaprasath., Orient. J. Chem., 27(4): 17111716 (2011).

13. Takagi. K., and Wada. H., 14th Intern. Cong. Soil Sci., 3: 196-132 (1990).

14. Wheeler. W. B., Marcel Dekker (2002). 